Abstract 20 Table 1 Patient demographics and CMR parameters

\begin{tabular}{|c|c|c|c|}
\hline & $\begin{array}{l}\text { Non-arrhythmia } \\
\text { group } \\
\mathrm{N}=23 \\
\text { (Standard } \\
\text { deviation) }\end{array}$ & $\begin{array}{l}\text { Arrhythmia } \\
\text { Group } \\
\mathrm{N}=32 \\
\text { (Standard } \\
\text { Deviation) }\end{array}$ & \\
\hline Age (yrs) & 29(5) & $36(9)$ & $\begin{array}{l}P< \\
0.05^{*}\end{array}$ \\
\hline Age of Fontan Procedure (yrs) & $6(4)$ & $11(9)$ & $\begin{array}{l}P< \\
0.05^{*}\end{array}$ \\
\hline Ejection fraction (\%) & $55(11)$ & $55(12)$ & $\begin{array}{l}P> \\
0.05^{*}\end{array}$ \\
\hline $\begin{array}{l}\text { End Diastolic Area of Fontan chamber } \\
\left(\mathrm{cm}^{2}\right)\end{array}$ & 19(8) & $30(16)$ & $\begin{array}{l}P< \\
0.05^{*}\end{array}$ \\
\hline $\begin{array}{l}\text { End Diastolic Longitudinal Value of } \\
\text { Fontan Chamber }\left(\mathrm{cm}^{2}\right)\end{array}$ & $4(1)$ & $6(2)$ & $\begin{array}{l}P< \\
0.05^{*}\end{array}$ \\
\hline $\begin{array}{l}\text { End Systolic Area of Fontan Chamber } \\
\left(\mathrm{cm}^{2}\right)\end{array}$ & $23(11)$ & $32(16)$ & $\begin{array}{l}P< \\
0.05^{*}\end{array}$ \\
\hline $\begin{array}{l}\text { End Systolic longitudinal Value Fontan } \\
\text { Chamber }\left(\mathrm{cm}^{2}\right)\end{array}$ & $5(1)$ & $6(2)$ & $\begin{array}{l}P< \\
0.05^{*}\end{array}$ \\
\hline
\end{tabular}

*P values represent significance level of between group t-tests

fraction $(p>0.05)$. There were no significant differences in atrial parameters between the two groups $(p>0.05)$, however all measures of the FC were statistically different with larger measures occurring in the AR group $(\mathrm{p}<0.05)$. Receiver operator characteristic curves were constructed for each of the atrium and FC variables. End diastolic area and FC longitudinal dimension produced statistically significant results (ROC $0.745 \mathrm{P}<$ 0.05 and $0.719 \mathrm{p}<0.05)$. Using an upper limit of $27 \mathrm{~cm}^{2}$ for end diastolic FC area odds ratio of AR was 8.57 ( $\mathrm{p}<0.05$ ) with a sensitivity of 0.596 and a specificity of 0.870 .

Conclusions Increasing AP FC size is associated with increased risk of AR.

\section{FEATURE TRACKING CARDIAC MAGNETIC RESONANCE TO ASSESS LV MECHANICS IN DIFFERENT CARDIAC OVERLOAD CAUSED BY AORTIC VALVE DISEASE}

\section{${ }^{1, *}$ A Scatteia, ${ }^{2}$ E Mara Vollema, ${ }^{2}$ M Leung, ${ }^{2} \mathrm{~N}$ Ajmone Marsan, ${ }^{1} \mathrm{~A}$ Baritussio, ${ }^{1} \mathrm{E}$ De Garate, ${ }^{1}$ A Ghosh Dastidar, ${ }^{1} \mathrm{~J}$ Rodrigues, ${ }^{2} \mathrm{JJ}$ Bax, ${ }^{2} \mathrm{~V}$ Delgado, ${ }^{1} \mathrm{C}$ Bucciarelli-Ducci. ${ }^{1}$ Bristol Heart Institute, University Hospitals Bristol NHS Foundation Trust., UK; ${ }^{2}$ Heart Lung Center, Department of Cardiology, Leiden University Medical Center, The Netherlands \\ 10.1136/heartjnl-2016-309668.21}

Background In aortic valve disease, left ventricular (LV) dimensions and ejection fraction are important parameters for decision making. However, the effects of pressure overload caused by aortic stenosis or/and volume overload, due to aortic regurgitation, lead to different LV remodelling, concentric and eccentric hypertrophy, respectively, which may differently alter LV mechanics. We aimed to characterise LV mechanics, in terms of longitudinal strain/deformation using feature tracking cardiac magnetic resonance (FT-CMR) in patients with various degree of aortic stenosis and aortic regurgitation and preserved LV ejection fraction (LVEF).

Methods Seventy-one patients (14 with normal valve function, 29 with aortic stenosis and 28 with aortic regurgitation), mean age $45 \pm 19$ years, $70 \%$ men, who underwent clinically indicated CMR and showed preserved LVEF (>50\%) were included. $\mathrm{LV}$ volumes, LVEF and mass were measured on steady-state free

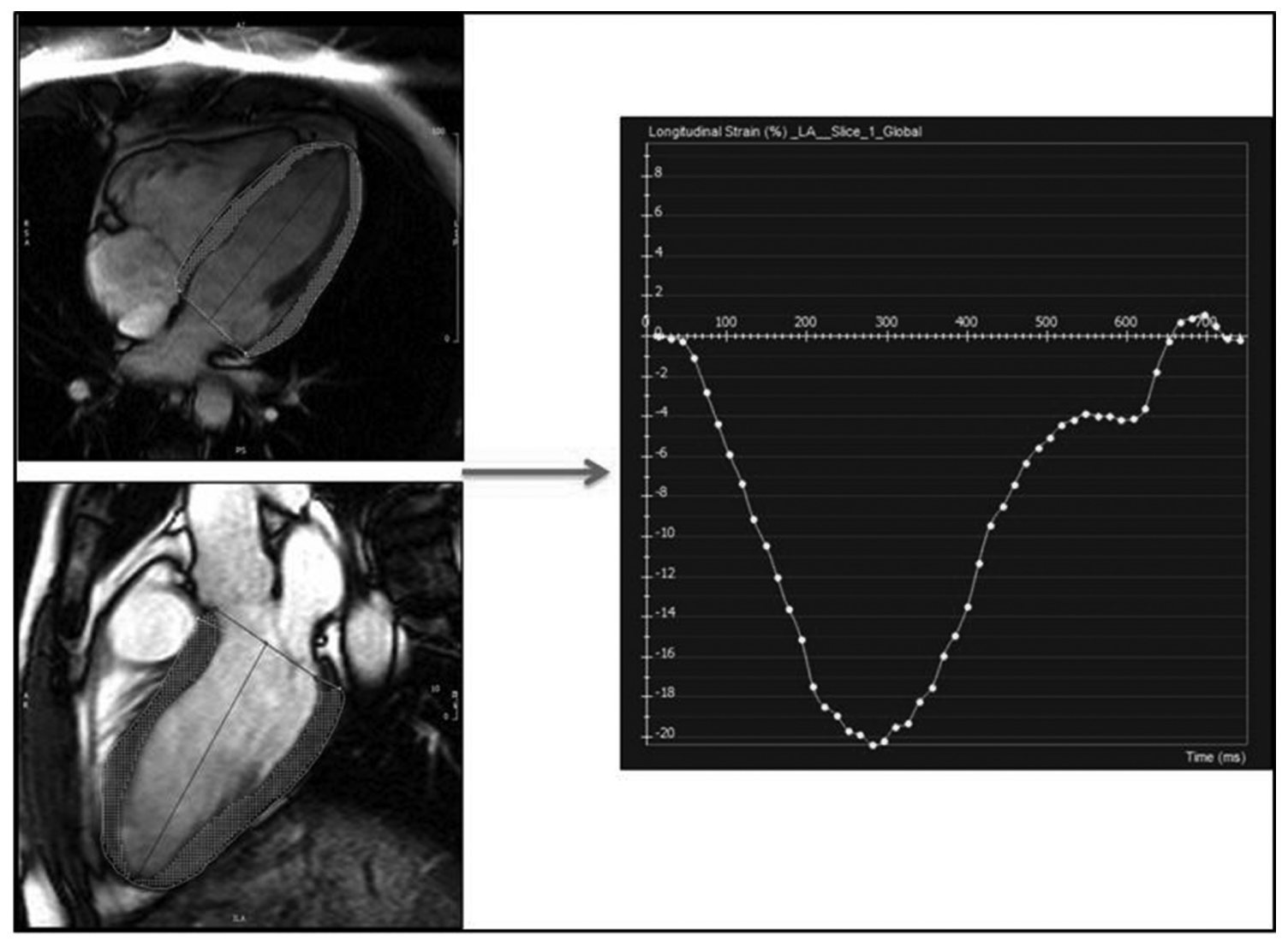

Abstract 21 Figure 1 Assessment of LV GLS with FT-CMR. From two long-axis SSFP cine images, the time-GLS curve is obtained and peak LV GLS is determined 
precession (SSFP) cine images. FT-CMR analysis was performed offline using tissue-tracking software (CVI42, Circle Cardiovascular Imaging Inc.) to estimate LV global longitudinal strain (GLS) from two long-axis SSFP cine images (Figure 1). To correct for the LV remodelling process, LV GLS was corrected for LV end-diastolic volume.

Results There were significant differences in LV volumes, mass and ejection fraction across the 3 groups of patients (Table 1): patients with aortic regurgitation showed significantly larger LV volumes, and lower LVEF compared to patients with normal aortic valve function and patients with aortic stenosis. There were no differences in LV GLS across the groups. However, after correcting for LV end-diastolic volume, patients with aortic regurgitation showed more impaired LV GLS as compared to the other groups.

\begin{tabular}{|c|c|c|c|c|}
\hline & $\begin{array}{l}\text { Normal valve } \\
\text { function }(n=14)\end{array}$ & $\begin{array}{l}\text { Aortic stenosis } \\
(n=29)\end{array}$ & $\begin{array}{l}\text { Aortic } \\
\text { regurgitation }(n= \\
\text { 28) }\end{array}$ & $\begin{array}{l}\text { ANOVA } \\
\text { p-value }\end{array}$ \\
\hline $\begin{array}{l}\text { Heart rate } \\
\text { (beats/min) }\end{array}$ & $71 \pm 8$ & $70 \pm 12$ & $64 \pm 13$ & 0.132 \\
\hline LVEDV (ml) & $135 \pm 33$ & $138 \pm 33$ & $186 \pm 50^{*}$ & $<0.001$ \\
\hline LVESV (ml) & $46 \pm 15$ & $43 \pm 16$ & $70 \pm 22^{*}$ & $<0.001$ \\
\hline LVEF (\%) & $65 \pm 5$ & $69 \pm 6$ & $62 \pm 5 \dagger$ & $<0.001$ \\
\hline LV mass (gr) & $120 \pm 29^{\#}$ & $153 \pm 36$ & $157 \pm 35$ & 0.005 \\
\hline GLS (\%) & $-19.2 \pm 3.4$ & $-19.3 \pm 3.6$ & $-19.8 \pm 3.0$ & 0.813 \\
\hline $\begin{array}{l}\text { LV GLS/ } \\
\text { LVEDV }\end{array}$ & $-0.15 \pm 0.05$ & $-0.14 \pm 0.04$ & $-0.12 \pm 0.04^{*}$ & 0.01 \\
\hline
\end{tabular}

${ }^{*} \mathrm{p}<0.001$ vs. Aortic stenosis and normal; $\dagger \mathrm{p}<0.001$ vs. Aortic stenosis; ${ }^{\#} \mathrm{p}<0.001$ vs. Aortic regurgitation and Aortic stenosis.

Conclusions LV mechanics significantly differ across normal functioning and different type of aortic valve dysfunction (stenosis and regurgitation), with aortic regurgitation showing the most impaired LV GLS corrected for LV end-diastolic volume, despite preserved LVEF.

\section{INTRA-VENTRICULAR MYOCARDIAL DEFORMATION STRAIN ANALYSIS IN HEALTHY VOLUNTEERS: REGIONAL VARIATION AND IMPLICATIONS FOR REGIONAL MYOCARDIAL DISEASE PROCESSES}

1,2,*A Scatteia, 'J Rodrigues, 'S Lyen, 'E De Gerate, ${ }^{1} \mathrm{~A}$ Baritussio, ${ }^{1} \mathrm{~A}$ Ghosh Dastidar ${ }^{1} \mathrm{G}$ Biglino, ${ }^{3} \mathrm{~A}$ Maceira, ${ }^{3} \mathrm{D}$ Pennell, ${ }^{1} \mathrm{C}$ Bucciarelli-Ducci. 'Bristol Heart Institute, University Hospitals Bristol NHS Foundation Trust, UK; ${ }^{2}$ Federico II, University of Naples, Naples, Italy; ${ }^{3}$ Brompton NIHR Cardiovascular Biomedical Research Unit, London, UK

10.1136/heartjnl-2016-309668.22

Ejection fraction (EF) is a traditional marker of systolic function. However, it may not detect early, subtle cardiac disease with regional predilection. The aim of this study was to define regional intra-ventricular variation in myocardial strain in a cohort of healthy volunteers using Tissue-tracking cardiac magnetic resonance (CMR).

Methods Healthy volunteers were recruited $(\mathrm{n}=94$, age range 20-79 years, 54\% male). CMR at $1.5 \mathrm{~T}$ was performed. Tissuetracking software (CVI42, Circle Cardiovascular Imaging Inc.) estimated myocardial strain from the long-axis and the short-axis steady-state free precession (SSFP) cine images (Figure 1). The entire cohort was analysed by two independent readers. Interobserver variability was also assessed. Myocardial segments were defined in accordance to the American Heart Association 16-segment model. Regional variations in circumferential and radial strain between basal, mid-cavity and apical segments as well as between left ventricle walls were assessed. Statistical analysis was performed using paired t test $(\mathrm{p}<0.05)$.

Results Inter-observer reproducibility analyses were excellent for mid-cavity and apical radial and circumferential strain values. On the other hand, reproducibility was not as good for basal segments for both deformation directions. Regional variations in strain (Table 1) revealed a statistically significant increase in deformation of the apical segments compared to the basal and mid-cavity ones for both radial and circumferential strain. Analysis of the different LV walls deformations indicated lowest values in the septum in all subjects, as well as across all age and gender subgroups.

Conclusion This is the first study to demonstrate that there is a positive gradient toward the apex in both circumferential and radial strain using CMR-derived myocardial strain analysis.

Abstract 22 Table 1 Regional strain values

\begin{tabular}{|c|c|c|c|c|c|c|c|c|c|c|c|}
\hline Strain $\%$ & Subgroup & & Basal & Mid-cavity & Apical & P-value* & Septal & Lateral & Anterior & Inferior & P-value** \\
\hline \multirow[t]{7}{*}{ Circumferential } & Gender & & & & & & & & & & \\
\hline & & Male $(n=51)$ & $-19 \pm 2$ & $-20 \pm 2$ & $-24 \pm 2$ & $<0.001$ & $-16 \pm 2$ & $-24 \pm 3$ & $-22 \pm 3$ & $-22 \pm 2$ & $<0.001$ \\
\hline & & Female $(n=43)$ & $-20 \pm 2$ & $-21 \pm 3$ & $-24 \pm 3$ & $<0.001$ & $-17 \pm 3$ & $-24 \pm 3$ & $-23 \pm 3$ & $-22 \pm 2$ & $<0.001$ \\
\hline & Age (years) & & & & & & & & & & \\
\hline & $20-39(n=28)$ & & $-19 \pm 2$ & $-19 \pm 2$ & $-23 \pm 3$ & $<0.001$ & $-15 \pm 3$ & $-23 \pm 3$ & $-22 \pm 3$ & $-21 \pm 2$ & $<0.001$ \\
\hline & $40-59(n=35)$ & & $-19 \pm 2$ & $-20 \pm 2$ & $-24 \pm 2$ & $<0.001$ & $-16 \pm 3$ & $-24 \pm 2$ & $-22 \pm 3$ & $-22 \pm 2$ & $<0.001$ \\
\hline & $60-79(n=31)$ & & $-20 \pm 2$ & $-22 \pm 2$ & $-25 \pm 3$ & $<0.001$ & $-17 \pm 2$ & $-26 \pm 2$ & $-24 \pm 2$ & $-23 \pm 2$ & $<0.001$ \\
\hline \multicolumn{12}{|l|}{ Radial } \\
\hline & Gender & & & & & & & & & & \\
\hline & & Male $(n=51)$ & $39 \pm 6$ & $37 \pm 7$ & $51 \pm 9$ & $<0.001$ & $28 \pm 6$ & $52 \pm 11$ & $46 \pm 9$ & $44 \pm 8$ & $<0.001$ \\
\hline & & Female $(n=43)$ & $43 \pm 8$ & $39 \pm 9$ & $52 \pm 11$ & $<0.001$ & $30 \pm 8$ & $52 \pm 11$ & $48 \pm 11$ & $45 \pm 8$ & $<0.001$ \\
\hline & Age (years) & & & & & & & & & & \\
\hline & & $20-39(n=28)$ & $39 \pm 7$ & $34 \pm 7$ & $48 \pm 10$ & $<0.001$ & $27 \pm 7$ & $47 \pm 9$ & $45 \pm 10$ & $42 \pm 6$ & $<0.001$ \\
\hline & & $40-59(n=35)$ & $40 \pm 6$ & $37 \pm 6$ & $52 \pm 10$ & $<0.001$ & $28 \pm 8$ & $50 \pm 9$ & $44 \pm 10$ & $42 \pm 9$ & $<0.001$ \\
\hline & & $60-79(n=31)$ & $44 \pm 9$ & $43 \pm 9$ & $55 \pm 11$ & $<0.001$ & $32 \pm 5$ & $60 \pm 11$ & $51 \pm 9$ & $49 \pm 8$ & $<0.001$ \\
\hline
\end{tabular}

